\title{
Bilateral Reduction of Corneal Sub-basal Nerves in Eyes with Recurrent Unilateral Posner-Schlossman Syndrome: An In Vivo Laser Scanning Confocal Microscopy Study
}

\section{Ruiping Huang ( $D$ 137395932@qq.com )}

Joint Shantou International Eye Center of Shantou University and The Chinese University of Hong Kong Li Tan

Joint Shantou International Eye Center of Shantou University and The Chinese University of Hong Kong Xiaoling Xie

Joint Shantou International Eye Center of Shantou University and The Chinese University of Hong Kong Tsz Kin Ng Joint Shantou International Eye Center of Shantou University and The Chinese University of Hong Kong Chukai Huang Joint Shantou International Eye Center of Shantou University and The Chinese University of Hong Kong

\section{Research Article}

Keywords: Posner-Schlossman syndrome, corneal sub-basal nerves, corneal endothelial cells, in vivo laser scanning confocal microscopy, recurrent

Posted Date: August 23rd, 2021

DOI: https://doi.org/10.21203/rs.3.rs-821608/v1

License: (c) (i) This work is licensed under a Creative Commons Attribution 4.0 International License.

Read Full License 


\section{Abstract}

PURPOSE. To evaluate the circumstances of corneal sub-basal nerves (CSNs) in the affected and contralateral unaffected eyes of patients with unilateral Posner-Schlossman Syndrome (PSS) through in vivo laser scanning confocal microscopy (LSCM) analysis.

METHODS. Total 74 eyes from 37 unilateral PSS patients and 38 eyes of control subjects were recruited. Sub-basal corneal nerve parameters in the in vivo LSCM, including the number and density of total nerves, main nerve trunks, and nerve branches were evaluated. Corneal epithelial and endothelial cell densities were also calculated.

RESULTS. The affected eyes of the patients with unilateral PSS demonstrated a significant decrease in all CSN parameters $(P<0.005)$, including the number and density of total nerves, main nerve trunks and nerve branches, as compared to the control eyes. Lower CSN value was observed in contralateral unaffected eyes for total nerve density as well as the number and density of main nerve trunks $(P<0.03)$ as compared to the control eyes. Moreover, corneal endothelial cell density was significantly reduced in affected eyes with PSS as compared to the control eyes $(P<0.015)$. Yet, significant reduction could only be observed in the affected and contralateral unaffected eyes of the patients with recurrent unilateral PSS. In addition, a positive correlation was found between endothelial cell density and the density of main nerve trunks in PSS-affected eyes $(r=0.33, P<0.05)$.

CONCLUSIONS. In vivo LSCM analysis revealed the reduction of CSNs in the affected and contralateral unaffected eyes of the patients with recurrent unilateral PSS. The positive correlation between corneal endothelial cell density and CSNs could suggest a potential link between corneal innervation and corneal endothelial cells.

Retrospectively registered ChiCTR2000037630, August 29, 2020

\section{Introduction}

Posner-Schlossman syndrome (PSS), also known as glaucomatocyclitic crisis, is usually characterized by the unilateral self-limited recurrent episodes of remarkable intraocular pressure (IOP) elevation accompanied by mild anterior chamber inflammation and fine white keratic precipitates (KP) [1, 2]. With the repeated attacks, $26.4 \%$ of PSS eyes would develop glaucoma, and $17 \%$ of eyes are progressively damaged and eventually need to receive glaucoma filtering surgery[3].

Recurrent anterior chamber inflammation and the appearance of KP could make an impact on the cornea[4]. Multiple studies have reported a decrease in corneal endothelial cell number in PSS eyes[5-7]. A recent study demonstrates an increase in corneal Langerhans cells and activation of corneal stromal cells in eyes with PSS through the in vivo laser scanning confocal microscopy (LSCM) analysis[8]. Although the etiology of PSS remains elusive, previous research studies suggest the possible involvement of viral infection in the pathogenesis of PSS[9]. Current in vivo LSCM studies demonstrated that both 
affected and contralateral unaffected eyes of patients with unilateral acute microbial keratitis have a significant bilateral loss of corneal sub-basal nerves (CSNs) as compared to the control subjects $[6,10,11]$. Cornea is an innervated tissue from the supply by the ophthalmic division of the trigeminal nerves, which function to maintain the integrity of the epithelium and wound healing through trophic functions of the nerves[12, 13]. The CSN parameters, including total nerves, main nerve trunks, and nerve branches, and the endothelial layers have been shown to be the important indicators for corneal health and diseases $[14,15]$.

In vivo LSCM is a non-invasive technique allowing the in vivo examination of human cornea visualized at all cellular levels by continuous confocal scanning[16]. Using LSCM, the density and morphology of corneal nerves could be evaluated in various corneal and systemic conditions, such as PSS, neurotrophic keratopathy, corneal infections and after corneal surgeries[8, 14, 17, 18]. Moreover, LSCM has also been applied in viral keratitis, keratoconus and corneal dystrophy to the disease[14]. Even though the involvement of corneal Langerhans cells, stromal cells and endothelial cell impactions has been shown in PSS, whether CSN parameters would be altered in PSS patients is still unclear. Herein, this study aimed to evaluate the number and density of CSNs in both affected and contralateral unaffected eyes of patients with unilateral PSS using the in vivo LSCM. In addition, the correlations of CSNs with corneal epithelial and endothelial cell densities were also analyzed.

\section{Patients And Methods}

\section{Study subjects}

This was a retrospective cross-sectional study, which was approved by the Ethics Committee for Human Medical Research at Joint Shantou International Eye Center of Shantou University and the Chinese University of Hong Kong and conducted in accordance with the tenets of the Declaration of Helsinki. Total 37 patients with diagnosis of unilateral PSS patients (74 eyes) and 38 control subjects were recruited at Joint Shantou International Eye Center of Shantou University and the Chinese University of Hong Kong between 2018 and 2020.

The eligible diagnostic criteria of Posner-Schlossman syndrome include[3, 19]: (1) Recurrent transient episodes of mild nongranulomatous cyclitis; (2) Symptoms of mild discomfort, halos, and slight blurring of vision; (3) Findings of corneal edema, elevated IOP, open angles, few cells and minimal flare, mydriasis, no iris posterior synechia and small-to-medium, discrete, round, white KP accumulating in the lower half of the cornea in the affected eye; (4) Attacks last for few hours to few weeks. The exclusion criteria include: (1) Bilaterally affected PSS; (2) Subjects with a history of ocular surgery; (3) other ocular diseases, except senile cataract, conjunctivitis, dry eye or refractive error; (4) spherical equivalent below -6.0 diopters. The control group included individuals without any history of eye diseases (except senile cataract), conjunctivitis, dry eye, refractive error with spherical equivalent below -6.0 diopters, a history of ocular surgery, current use of contact lenses or long-term use of eye drops. All included subjects received 
complete ophthalmic examinations, including measurement of refraction, best corrected visual acuity, IOP, anterior segment evaluation by slit-lamp biomicroscope and in vivo LSCM.

\section{In Vivo Laser Scanning Confocal Microscopy}

In vivo LSCM analysis (Heidelberg Retina Tomograph 3 with the Rostock Cornea Module; Heidelberg Engineering $\mathrm{GmbH}$, Heidelberg, Germany) was performed in all study subjects ${ }^{[3,19]}$. A helium neon diode laser source with a wavelength of $670 \mathrm{~nm}$ was adopted. Two-dimensional images of the in vivo LSCM were captured as $384 \times 384$ pixels over an area of $400 \times 400 \mu \mathrm{m}^{2}\left(160,000 \mu \mathrm{m}^{2}\right)$ at a selectable corneal depth. One drop of topical anesthesia ( $0.5 \%$ proparacaine hydrochloride eye drops; s.a. ALCONCOUVREUR n.v) was instilled in each examined eye. A disposable sterile cap (Tomo-Cap, Heidelberg, Germany) was mounted over the lens after covering the lens with $0.2 \%$ Carbomer ere gel (Dr. Gerhard Mann Chem -Pharm Fabrik $\mathrm{GmbH}$ ) below. Corneal images were obtained by asking subjects to fix their gaze at a red fixation light, and the lens was advanced manually until the images were obtained at specific corneal locations. Sequential scans were captured from the corneas of both eyes in the patients with unilateral PSS, and only one randomly selected eye in the control subjects. The operator adjusted the position of the objective lens until a bright image of the endothelium was visible in the center of the field.

\section{Image Analysis}

Digital images were stored in a workstation with the Heidelberg built-in software (Heidelberg Eye Explorer version 1.5.10.0, Heidelberg Engineering GmbH 2005, Heidelberg, Germany). An experienced masked observer selected the three best-focused representative images of the CSN plexus, epithelial and endothelial cell layer analysis from the central cornea of all subjects, who satisfied the criteria for selection. The criteria to select the images were the best-focused complete images, with the whole image in the same layer and good contrast, and at least 50 good-quality images. The CSN plexus was chosen from the basal epithelial layer and anterior to the Bowman's layer. Epithelial cell and the endothelial cell densities were quantified by the computer built-in in vivo LSCM corresponding software. A semiautomated tracing program NeuronJ[20], a plug-in for ImageJ distributed by the National Institutes of Health (http://rsb.info.nih.gov/ij/http://rsb.info.nih.gov/ij/,http://www.imagescience.org/ meijering/software/neuronj/; accessed July 12, 2020), was adopted for the CSN analysis. Main nerve trunk was defined as the nerve trunk in 1 image that did not branch from other nerve and nerve branch was defined as branch emerging from the main nerve trunk in the same image. The total nerves were defined as all nerves, including main nerve and branches in 1 image[21].The density and number of nerves were analyzed by tracing all visible nerve fibers in the image, and the length of the nerve fibers was calculated as millimeters $(\mathrm{mm}) / \mathrm{mm}^{2}$ and number $(\mathrm{n}) /$ frame.

\section{Statistical Analysis}


Statistical analysis was performed with SPSS version 25.0 (SPSS Inc, Chicago, IL, USA). Distribution of data was analyzed by the Kolmogorov-Smirnov test. As most of the nerve parameters were non-normally distributed, comparison between two groups was analyzed by the Kruskal-Wallis $\mathrm{H}$ test and adjusted by Bonferroni correction for multiple testing correction. Correlation analysis was performed using Spearman's rank correlation test. Categorical variables were compared using the Fisher's exact test. All the data are presented as mean \pm standard error of mean. Pless than 0.05 was considered as statistically significant.

\section{Results}

\section{Demographics of the study subjects}

Total 37 affected and 37 contralateral unaffected eyes from 37 patient diagnosed with unilateral PSS (mean age: $40.6 \pm 15.3$ years; 22 males and 15 females) and 38 eyes from 38 control subjects (mean age: $40.3 \pm 14.9$ years; 19 males and 19 females) were studied. (Table 1 ). No statistically significant differences were found in age $(P=0.80)$ and gender $(P=0.50)$ between the PSS patients and the control subjects. Moreover, there was also no statistically significant differences in the numbers of left and right eyes studied between the PSS patients and the control subjects $(P=0.50)$. However, the IOP in the affected eyes of the PSS patients was significantly smaller than that of the control subjects $(P=0.0001)$.

\section{Reduction of corneal endothelial cells in the affected eyes of patients with unilateral Posner-Schlossman Syndrome}

The in vivo LSCM analysis on the unilateral PSS patients revealed that the epithelial cell density of the affected eyes ( $5237 \pm 809$ cells $/ \mathrm{mm}^{2}$ ) showed no statistically significant differences as compared to the unaffected eyes $\left(5441 \pm 820\right.$ cells $\left./ \mathrm{mm}^{2}, P=0.690\right)$ and the control eyes $\left(5665 \pm 614\right.$ cells $/ \mathrm{mm}^{2}, P=$ 0.690 ; Table 2). Instead, the endothelial cell density of the affected eyes of the unilateral PSS patients $\left(2627 \pm 322\right.$ cells $\left./ \mathrm{mm}^{2}\right)$ was significantly reduced as compared to the control eyes ( $2862 \pm 298$ cells $/ \mathrm{mm}^{2}, P=0.014$; Fig.1D and $1 \mathrm{~F}$ ). Yet, the endothelial cell density of the unaffected eyes of the unilateral PSS patients $\left(2714 \pm 362\right.$ cells $\left./ \mathrm{mm}^{2}\right)$ showed no statistically significant differences as compared to the affected eyes of the unilateral PSS patients $(P=0.380)$ and the control eyes $(P=0.590)$.

\section{Reduction of corneal sub-basal nerves in the affected and unaffected eyes of patients with unilateral Posner- Schlossman Syndrome}


For the affected eyes of the patients with unilateral PSS, the number of total nerves $(9.7 \pm 3.4 /$ frame, $P=$ $0.0001)$, main nerve trunks $(4.8 \pm 1.6 /$ frame, $P=0.001)$, and nerve branches $(4.9 \pm 2.9 /$ frame, $P=0.005)$ as well as the density of total nerves $\left(2.3 \pm 0.7 \mathrm{~mm} / \mathrm{mm}^{2}, P=0.0001\right)$, main nerve trunks $(1.6 \pm 0.5$ $\left.\mathrm{mm} / \mathrm{mm}^{2}, P=0.0001\right)$ and nerve branches $\left(0.6 \pm 0.4 \mathrm{~mm} / \mathrm{mm}^{2}, P=0.0001\right)$ were significantly lower than the control eyes (number: total nerves $13.8 \pm 4.9$ /frame, main nerve trunks $6.2 \pm 1.6 /$ frame, nerve branches $7.6 \pm 4.6 /$ frame; density: total nerves $3.3 \pm 0.8 \mathrm{~mm} / \mathrm{mm}^{2}$, main nerve trunks $2.3 \pm 0.6 \mathrm{~mm} / \mathrm{mm}^{2}$, nerve branches $1.1 \pm 0.6 \mathrm{~mm} / \mathrm{mm}^{2}$; Table 2 and Fig. 2). Notably, the number of main nerve trunks (5.1 \pm $1.6 /$ frame, $P=0.027)$ as well as the density of total nerves $\left(2.8 \pm 0.6 \mathrm{~mm} / \mathrm{mm}^{2}, P=0.021\right)$ and main nerve trunks $\left(1.8 \pm 0.4 \mathrm{~mm} / \mathrm{mm}^{2}, P=0.010\right)$ in the contralateral unaffected eyes of the patients with unilateral PSS were also significantly lower than the control eyes. Besides, the number of total nerves $(P=$ 0.006) and nerve branches $(P=0.004)$ as well as the density of total nerves $(P=0.015)$ and nerve branches $(P=0.010)$ in the affected eyes of the patients with unilateral PSS were also significantly lower than the contralateral unaffected eyes. In addition, a weak but significant positive correlation was observed between the endothelial cell density and the density of main nerve trunks in the affected eyes of the patients with unilateral PSS ( $r=0.33, P=0.048$; Fig. 3 ).

\section{Reduction of endothelial cell density and corneal sub-basal nerves in patients with recurrent unilateral Posner- Schlossman Syndrome}

The 37 PSS patients were subdivided into 24 recurrent PSS and 13 non-recurrent patients as proven to be recurrent at the follow-up visits. For the affected eyes of the patients with recurrent PSS, the endothelial cell density $\left(2578 \pm 381\right.$ cells $\left./ \mathrm{mm}^{2}, P<0.0001\right)$, the number of total nerves $(9.3 \pm 2.9 /$ frame, $P<0.0001)$, main nerve trunks (4.8 $\pm 1.7 /$ frame, $P<0.0001)$, and nerve branches $(4.5 \pm 2.4 /$ frame, $P<0.0001)$ as well as the density of total nerves $\left(2.1 \pm 0.7 \mathrm{~mm} / \mathrm{mm}^{2}, P<0.050\right)$, main nerve trunks $\left(1.5 \pm 0.5 \mathrm{~mm} / \mathrm{mm}^{2}, P<\right.$ $0.050)$ and nerve branches $\left(0.6 \pm 0.3 \mathrm{~mm} / \mathrm{mm}^{2}, P<0.050\right)$ were significantly lower than the control eyes (Table 3凶Fig. 4). For the contralateral unaffected eyes of the patients with recurrent PSS, also showed statistically significant reduction in the total nerve density $\left(2.8 \pm 0.7 \mathrm{~mm} / \mathrm{mm}^{2}, P=0.034\right)$ as compared to the control eyes. On the contrary, the affected and unaffected eyes of the patients with non-recurrent PSS did not statistically significant differences as compared to the control eyes.

\section{Discussion}

In the current study, we demonstrated that not only the endothelial cell density showed a significant reduction in the affected eyes of the patients with unilateral PSS, but also the number and density of CSNs, especially the contralateral unaffected eyes, as compared to the age-matched controls. We, for the first time, evaluated the in vivo LSCM images of corneal nerves and endothelial cells together in the 
patients with unilateral PSS. Our results indicated that unilateral corneal endothelial cells and bilateral corneal nerves were significantly reduced in patients with unilateral PSS.

In the current study, we observed a significant reduction of endothelial cell density only in the affected eyes of the patients with unilateral PSS. Endothelial cell density decease in the eyes affected with PSS has been reported in previous study[22-24] , but not compared between the unaffected eyes and the normal control eyes. Corneal endothelial cell loss has been suggested to be positive correlated with the cytomegalovirus viral load of aqueous humor[25]. Significant reduction of endothelial cell density was only shown in the PSS-affected eyes instead of both eyes, potentially attributed to different viral load between the PSS-affected and unaffected eyes.

Using the in vivo LSCM, we observed a significant lower number and density of CSNs in the affected eyes of the patients with unilateral PSS, as compared to the control eyes. Notably, in the contralateral unaffected eyes of all patients with unilateral PSS, we also observed a significant reduction in the number of main nerve trunks as well as the density of total nerves and main nerve trunks as compared to the control eyes. We further showed a positive correlation between endothelial cell density and the density of main nerve trunks in the affected eyes of the patients with unilateral PSS. Although bilateral changes of CSN has been described in unilateral virus keratitis[6,26] and after unilateral cataract surgery[27], we, for the first time, demonstrated the bilateral corneal nerve reduction in the patients with unilateral PSS. However, the exact mechanisms involved in corneal nerve degeneration in eyes with PSS were not well characterized. The possible cause of PSS could be viral infection, especially cytomegalovirus and herpes simplex virus $[24,28]$. In contrast, we postulated that PSS could be related to HLA-B27 anterior uveitis and acute attack of primary angle closure with the involvement of central Langerhans cells and keratocyte activation[8] as the CSN reduction in patients with PSS are located in the same layer of the Langerhans cells.

The bilateral nerve reduction in the patients with unilateral PSS described here could be explained by the CNS-mediated contralateral effects although we cannot exclude subclinical infection in the contralateral eyes. The nervous interdependence in different regions of human body affecting the opposite side of the unaffected structures have been described[29]. There are also well-documented events that peripheral trigeminal nerve fibers directly project to bilateral areas of brainstem nuclei and caudal medulla that affects the opposite side of the unaffected structures[30,31]. The anatomical pathway could involve an extensive bilateral central projection sending to the contralateral peripheral Gasserian ganglion[32]. A previous study reported that the patients undergoing unilateral microincisional cataract surgery show bilateral reduction of CSN plexus at 1 month postoperatively[27]. Those findings confirm the evidence that corneal nervous interdependence between the affected and unaffected eyes. The changes in the contralateral unaffected eyes could be secondary to the affected eyes as the CSNs of unaffected eyes were higher than the affected eyes. Neuropeptides and neurotrophins, such as substance P, VIP, nerve growth factor, brain-derived neurotrophic factor, and glial cell-derived neurotrophic factor are found in the cornea with anti-inflammatory and antiapoptotic effect[33,34]. The presence of contralateral corneal nerve impairment was also believed to be related to the sympathetic immune response through the local 
release of proinflammatory neuropeptides by afferent dysfunctional neurons[10]. Furthermore, this study demonstrated a weak positive correlation between endothelial cell density and the density of main nerve trunks in the affected eyes of the patients with unilateral PSS. The reduction of endothelial cell density could potentially be attributed to the reduction of corneal nerves, which in turn could lead to the decreased levels of neuropeptides, subsequently resulting in endothelial cell loss[35].

When we compared the recurrent and non-recurrent patients with PSS, the endothelial cell density as well as the number and density of total nerves, main nerve trunks and nerve branches of the affected eyes of the patients with recurrent PSS were significantly lower as compared to the control eyes, but the reduction was not observed in the non-recurrent patients. A Chinese study on predominant PSS reported that one fourth of the PSS eyes shows glaucomatous damage development because of repeated attacks[3]. These imply that recurrent episode could exacerbate the damage of PSS. However, a previous study indicated that corneal nerve density of $1064 \mu \mathrm{m} /$ frame is sufficient for normal sensation[6]. This could explain why the nerve damage in PSS patients did have the clinical symptoms.

The current study has several limitations. First, there could be unnoticed changes because the range of in vivo LSCM has its own limit. Second, some morphological parameters of cornea nerves have not been evaluated, such as tortuosity. Third, the retrospective study design of this study was not able to determine if the nerve reduction and the endothelial cell loss were progressive and if there were other influencing factors, such as treatment and IOP level during each episode affecting the nerve and the endothelial cells. The follow-up visits were limited preventing us to assess the persistence or resolution of these changes over time as well as the long-term implications of the contralateral sympathetic nervous response.

In summary, our results, based on the in vivo LSCM analysis, revealed the reduction of endothelial cell density and CSNs in the affected and contralateral unaffected eyes of the patients with unilateral PSS, especially the recurrently affected eyes. Further longitudinal studies are warranted to document the sequential changes and to illustrate their mechanisms.

\section{Declarations}

\section{Funding}

This study was supported by internal grant from the Joint Shantou International Eye Center of The Shantou University and The Chinese University of Hong Kong (project code:19-032 to H-CK) and the Special Fund for Science and Technology of Guangdong Province (project code: 2019ST016 to H-CK) and the Grant for Key Disciplinary Project of Clinical Medicine under the Guangdong High-level University Development Program, China.

\section{Competing interests}


The authors declare no potential competing interests.

\section{Availability of data and material}

Data can be shared upon request.

\section{Code availability}

Data can be shared upon request.

\section{Author contributions}

$\mathrm{H}-\mathrm{CK}$ proposed the original idea, provided guidance for clinical knowledge and modified the article. H-RP collected date, completed the statistical analysis and authored the first draft of the manuscript. TL helped filtered data that met the inclusion criteria. X-XL helped analyze of the data. N-TK gave critical revision of article and revised the article.

\section{Ethics approval}

Approval was obtained from the Ethics Committee of the Joint Shantou International Eye Center of The Shantou University and The Chinese University of Hong Kong. The procedures used in this study adhere to the tenets of the Declaration of Helsinki.

\section{Consent for publication}

All authors have agreed to the submission for the article

\section{References}

1. A POSNER ASCHLOSSMAN (1948) Syndrome of unilateral recurrent attacks of glaucoma with cyclitic symptoms. Archives of ophthalmology (Chicago, III.: 1929)39:517-535 https://doi.org/10.1001/archopht.1948.00900020525007

2. Shazly TA, Aljajeh M, MA Latina (2011) Posner-schlossman glaucomatocyclitic crisis. Semin Ophthalmol 26:282-284. https://doi.org/10.3109/08820538.2011.605821

3. Jap A, Sivakumar M, Chee SP (2001) Is posner schlossman syndrome benign? Ophthalmology108:913-918 https://doi.org/10.1016/s0161-6420(01)00551-6

4. Olsen T (1981) Transient changes in specular appearance of the corneal endothelium and in corneal thickness during anterior uveitis. Acta Ophthalmol (Copenh 59:100-109. 
https://doi.org/10.1111/j.1755-3768.1981.tb06717.x

5. Igarashi N, Honjo M, Kaburaki T, Aihara M (2020) Effects of rock inhibitors on apoptosis of corneal endothelial cells in cmv-positive posner-schlossman syndrome patients. Invest Ophthalmol Vis Sci 61:5. https://doi.org/10.1167/iovs.61.10.5

6. CC Su FR, Hu TH, Wang JY, Huang et al (2014) Clinical outcomes in cytomegalovirus-positive posnerschlossman syndrome patients treated with topical ganciclovir therapy. Am J Ophthalmol.158:1024-1031.e1022 https://doi.org/10.1016/j.ajo.2014.08.007

7. Pillai CT, Dua HS, Azuara-Blanco A, Sarhan AR (2000) Evaluation of corneal endothelium and keratic precipitates by specular microscopy in anterior uveitis. $\mathrm{Br} \mathrm{J}$ Ophthalmol 84:1367-1371. https://doi.org/10.1136/bjo.84.12.1367

8. Hong Y, Wang M, Wu L (2017) In vivo confocal microscopy of posner-schlossman syndrome: Comparison with herpes simplex keratitis, hla-b27 anterior uveitis and acute attack of primary angle closure. Sci Rep 7:9832. https://doi.org/10.1038/s41598-017-10496-7

9. Niederer RL, McGhee CN (2010) Clinical in vivo confocal microscopy of the human cornea in health and disease. Prog Retin Eye Res 29:30-58. https://doi.org/10.1016/j.preteyeres.2009.11.001

10. Cruzat A, Schrems WA, Schrems-HoesI LM, Cavalcanti BM et al (2015) Contralateral clinically unaffected eyes of patients with unilateral infectious keratitis demonstrate a sympathetic immune response. Invest Ophthalmol Vis Sci 56:6612-6620. https://doi.org/10.1167/iovs.15-16560

11. Moein HR, Kheirkhah A, Muller RT, Cruzat AC et al (2018) Corneal nerve regeneration after herpes simplex keratitis: A longitudinal in vivo confocal microscopy study. Ocul Surf 16:218-225. https://doi.org/10.1016/j.jtos.2017.12.001

12. Takusagawa HL, Liu Y, Wiggs JL (2011) Infectious theories of posner-schlossman syndrome. Int Ophthalmol Clin 51:105-115. https://doi.org/10.1097/IIO.0b013e31822d6ab4

13. Chee SP, Jap A (2008) Presumed fuchs heterochromic iridocyclitis and posner-schlossman syndrome: Comparison of cytomegalovirus-positive and negative eyes. Am J Ophthalmol.146:883889.e881 https://doi.org/10.1016/j.ajo.2008.09.001

14. Cruzat A, Pavan-Langston D, Hamrah P (2010) In vivo confocal microscopy of corneal nerves: Analysis and clinical correlation. Semin Ophthalmol 25:171-177. https://doi.org/10.3109/08820538.2010.518133

15. Hamrah P, Cruzat A, Dastjerdi MH, H Prüss et al (2013) Unilateral herpes zoster ophthalmicus results in bilateral corneal nerve alteration: An in vivo confocal microscopy study. Ophthalmology 120:40-47 https://doi.org/10.1016/j.ophtha.2012.07.036

16. Beuerman RW, Schimmelpfennig B (1980) Sensory denervation of the rabbit cornea affects epithelial properties. Exp Neurol 69:196-201. https://doi.org/10.1016/0014-4886(80)90154-5

17. Bonini S, Rama P, Olzi D, Lambiase A (2003) Neurotrophic keratitis. Eye (London England 17:989995. https://doi.org/10.1038/sj.eye.6700616

18. Hamrah P, Cruzat A, Dastjerdi MH, Zheng L et al (2010) Corneal sensation and subbasal nerve alterations in patients with herpes simplex keratitis: An in vivo confocal microscopy study. 
Ophthalmology117:1930-1936 https://doi.org/10.1016/j.ophtha.2010.07.010

19. Jiang JH, Zhang SD, Dai ML, Yang JY et al (2017) Posner-schlossman syndrome in wenzhou, china: A retrospective review study. $\mathrm{Br} \mathrm{J}$ Ophthalmol 101:1638-1642.

https://doi.org/10.1136/bjophthalmol-2016-309863

20. Meijering E, Jacob M, Sarria JC, Steiner P et al (2004) Design and validation of a tool for neurite tracing and analysis in fluorescence microscopy images. Cytometry Part A: the journal of the International Society for Analytical Cytology 58:167-176. https://doi.org/10.1002/cyto.a.20022

21. Hamrah P, Qazi Y, Shahatit B, Dastjerdi MH et al (2017) Corneal nerve and epithelial cell alterations in corneal allodynia: An in vivo confocal microscopy case series. The ocular surface15:139-151. https://doi.org/10.1016/j.jtos.2016.10.002

22. Wang EF, Misra SL, Patel DV (2015) In vivo confocal microscopy of the human cornea in the assessment of peripheral neuropathy and systemic diseases. BioMed research international2015:951081 https://doi.org/10.1155/2015/951081

23. Yamaguchi T, Hamrah P, Shimazaki J (2016) Bilateral alterations in corneal nerves, dendritic cells, and tear cytokine levels in ocular surface disease. CorneaS65-S70 https://doi.org/10.1097/ico.0000000000000989

24. Murata K, Ishida K, Ozawa K, Sawada A et al (2019) The characteristics of posner-schlossman syndrome: A comparison in the surgical outcome between cytomegalovirus-positive and cytomegalovirus-negative patients. Medicine98:e18123 https://doi.org/10.1097/md.0000000000018123

25. Miyanaga M, Sugita S, Shimizu N, Morio T et al (2010) A significant association of viral loads with corneal endothelial cell damage in cytomegalovirus anterior uveitis. $\mathrm{Br} \mathrm{J}$ Ophthalmol 94:336-340. https://doi.org/10.1136/bjo.2008.156422

26. Waduthantri S, Zhou L, SP Chee (2018) Intra-cameral level of ganciclovir gel, $0.15 \%$ following topical application for cytomegalovirus anterior segment infection: A pilot study. PLoS One13:e0191850 https://doi.org/10.1371/journal.pone.0191850

27. Giannaccare G, Bernabei F, Pellegrini M, Guaraldi F et al (2021) Bilateral morphometric analysis of corneal sub-basal nerve plexus in patients undergoing unilateral cataract surgery: A preliminary in vivo confocal microscopy study. Br J Ophthalmol 105:174-179.

https://doi.org/10.1136/bjophthalmol-2019-315449

28. Yamamoto S, Pavan-Langston D, Tada R, Yamamoto R et al (1995) Possible role of herpes simplex virus in the origin of posner-schlossman syndrome. Am J Ophthalmol 119:796-798. https://doi.org/10.1016/s0002-9394(14)72788-6

29. Oaklander AL, Romans K, Horasek S, Stocks A et al (1998) Unilateral postherpetic neuralgia is associated with bilateral sensory neuron damage. Ann Neurol 44:789-795. https://doi.org/10.1002/ana.410440513

30. Hökfelt T, Zhang X, Wiesenfeld-Hallin Z (1994) Messenger plasticity in primary sensory neurons following axotomy and its functional implications. Trends Neurosci 17:22-30. 
https://doi.org/10.1016/0166-2236(94)90031-0

31. Vannas A, Ahonen R, J Mäkitie (1983) Corneal endothelium in herpetic keratouveitis. Archives of ophthalmology (Chicago, III.: 1960)101:913-915 https://doi.org/10.1001/archopht.1983.01040010913011

32. Jacquin MF, Chiaia NL, Rhoades RW (1990) Trigeminal projections to contralateral dorsal horn: Central extent, peripheral origins, and plasticity. Somatosens Mot Res 7:153-183. https://doi.org/10.3109/08990229009144705

33. You L, Kruse FE, Völcker HE (2000) Neurotrophic factors in the human cornea. Invest Ophthalmol Vis Sci 41:692-702

34. Lambiase A, Manni L, Bonini S, Rama P et al (2000) Nerve growth factor promotes corneal healing: Structural, biochemical, and molecular analyses of rat and human corneas. Invest Ophthalmol Vis Sci 41:1063-1069

35. Müller RT, Pourmirzaie R, Pavan-Langston D, Cavalcanti BM et al (2015) In vivo confocal microscopy demonstrates bilateral loss of endothelial cells in unilateral herpes simplex keratitis. Invest Ophthalmol Vis Sci 56:4899-4906. https://doi.org/10.1167/iovs.15-16527

\section{Tables}

\section{TABLE 1}

Demographics of Control subjects and Patients With unilateral PSS

\begin{tabular}{|llll|}
\hline & Controls & PSS & $P$ \\
\hline Number of patients, $\mathrm{n}$ & 38 & 37 & - \\
\hline Age, years & $40.3 \pm 14.9$ & $40.6 \pm 15.3$ & $0.8^{*}$ \\
\hline Gender, male/female & $19 / 19$ & $22 / 15$ & $0.5^{\#}$ \\
\hline Number of eye, right/left & $22 / 16$ & $19 / 18$ & $0.5^{\#}$ \\
\hline Time since first episode, months & - & $26.4 \pm 38.6$ & - \\
\hline IOP, affected/unaffected, mmHg & $22.6 \pm 11.7$ & $14.9 \pm 2.8 / 16.2 \pm 3.4$ & $0.0001^{*} / 0.06^{*}$ \\
\hline $\begin{array}{l}\text { Data presented as mean } \pm \text { standard deviation. } \\
\text { *t-test }\end{array}$ & & \\
\hline \# Fisher's exact test & & & \\
\hline
\end{tabular}


TABLE 2

In Vivo Confocal Microscopy Parameters of Controls and Patients With PSS

\begin{tabular}{|c|c|c|c|c|c|c|}
\hline & Controls & $P^{\star}$ & $\begin{array}{l}\text { Affected } \\
\text { Eye }\end{array}$ & $P^{\star}$ & $\begin{array}{l}\text { Contralateral } \\
\text { Unaffected Eye }\end{array}$ & $\mathrm{P}^{\#}$ \\
\hline $\begin{array}{l}\text { Epithelial cell density, } \\
\text { cells } / \mathrm{mm}^{2}\end{array}$ & $5665 \pm 614$ & 0.69 & $5237 \pm 809$ & 0.69 & $5441 \pm 820$ & 0.69 \\
\hline $\begin{array}{l}\text { Endothelial cell density, } \\
\text { cells } / \mathrm{mm}^{2}\end{array}$ & $2862 \pm 298$ & 0.014 & $2627 \pm 322$ & 0.59 & $2714 \pm 362$ & 0.38 \\
\hline $\begin{array}{l}\text { Total nerve density, } \\
\mathrm{mm} / \mathrm{mm}^{2}\end{array}$ & $3.3 \pm 0.8$ & 0.0001 & $2.3 \pm 0.7$ & 0.021 & $2.8 \pm 0.6$ & 0.015 \\
\hline $\begin{array}{l}\text { Main nerve trunks density, } \\
\mathrm{mm} / \mathrm{mm}^{2}\end{array}$ & $2.3 \pm 0.6$ & 0.0001 & $1.6 \pm 0.5$ & 0.01 & $1.8 \pm 0.4$ & 0.27 \\
\hline $\begin{array}{l}\text { Nerve branches density, } \\
\mathrm{mm} / \mathrm{mm}^{2}\end{array}$ & $1.1 \pm 0.6$ & 0.0001 & $0.6 \pm 0.4$ & 0.81 & $0.9 \pm 0.4$ & 0.01 \\
\hline $\begin{array}{l}\text { Total nerve number, } \\
\text { n/frame }\end{array}$ & $13.8 \pm 4.9$ & 0.0001 & $9.7 \pm 3.4$ & 1.0 & $12.2 \pm 3.6$ & 0.006 \\
\hline $\begin{array}{l}\text { Main nerve trunks } \\
\text { number, } n / \text { frame }\end{array}$ & $6.2 \pm 1.6$ & 0.001 & $4.8 \pm 1.6$ & 0.027 & $5.1 \pm 1.6$ & 1.0 \\
\hline $\begin{array}{l}\text { Nerve branches number, } \\
\mathrm{n} / \text { frame }\end{array}$ & $7.6 \pm 4.6$ & 0.005 & $4.9 \pm 2.9$ & 1.0 & $7.0 \pm 2.9$ & 0.004 \\
\hline \multicolumn{7}{|c|}{ Data presented as mean \pm standard deviation. } \\
\hline \multicolumn{7}{|c|}{$\begin{array}{l}\text { * Comparison between studied groups and controls, \# comparison between affected and contralateral } \\
\text { unaffected eyes (Kruskal-Wallis } \mathrm{H} \text { test with Bonferroni post hoc analysis). }\end{array}$} \\
\hline \multicolumn{7}{|c|}{$P<0.05$ was considered statistically significant. } \\
\hline
\end{tabular}

\section{TABLE 3}

Comparisons In Vivo Confocal Microscopy Parameters of Controls and Patients With recurrent or nonrecurrent PSS 


\begin{tabular}{|c|c|c|c|c|c|}
\hline & \multirow[t]{2}{*}{ Controls } & \multicolumn{2}{|l|}{ Affected Eye } & \multicolumn{2}{|c|}{$\begin{array}{l}\text { Contralateral Unaffected } \\
\text { Eye }\end{array}$} \\
\hline & & recurrent & nonrecurrent & recurrent & nonrecurrent \\
\hline $\begin{array}{l}\text { Epithelial cell density, } \\
\text { cells } / \mathrm{mm}^{2}\end{array}$ & $5665 \pm 614$ & $5184 \pm 887$ & $5252 \pm 800$ & $5502 \pm 831$ & $5529 \pm 839$ \\
\hline $\begin{array}{l}\text { Endothelial cell } \\
\text { density, cells } / \mathrm{mm}^{2}\end{array}$ & $2862 \pm 298$ & $2578 \pm 381^{\#}$ & $2733 \pm 184$ & $2699 \pm 377$ & $2670 \pm 358$ \\
\hline $\begin{array}{l}\text { Total nerve density, } \\
\mathrm{mm} / \mathrm{mm}^{2}\end{array}$ & $3.3 \pm 0.8$ & $2.1 \pm 0.7^{*}$ & $2.6 \pm 0.7$ & $2.8 \pm 0.7^{\#}$ & $2.7 \pm 0.6$ \\
\hline $\begin{array}{l}\text { Main nerve trunks } \\
\text { density, } \mathrm{mm} / \mathrm{mm}^{2}\end{array}$ & $2.3 \pm 0.6$ & $1.5 \pm 0.5^{\star}$ & $1.8 \pm 0.4$ & $1.9 \pm 0.5$ & $1.9 \pm 0.5$ \\
\hline $\begin{array}{l}\text { Nerve branches } \\
\text { density, } \mathrm{mm} / \mathrm{mm}^{2}\end{array}$ & $1.1 \pm 0.6$ & $0.6 \pm 0.3^{\star}$ & $0.8 \pm 0.5$ & $0.8 \pm 0.3$ & $0.8 \pm 0.3$ \\
\hline $\begin{array}{l}\text { Total nerve number, } \\
\text { n/frame }\end{array}$ & $13.8 \pm 4.9$ & $9.3 \pm 2.9^{\#}$ & $10.7 \pm 4.0$ & $12.5 \pm 4.2$ & $11.8 \pm 3.4$ \\
\hline $\begin{array}{l}\text { Main nerve trunks } \\
\text { number, } \mathrm{n} / \text { frame }\end{array}$ & $6.2 \pm 1.6$ & $4.8 \pm 1.7^{\#}$ & $5.2 \pm 1.4$ & $5.4 \pm 1.7$ & $5.4 \pm 1.7$ \\
\hline $\begin{array}{l}\text { Nerve branches } \\
\text { number, } n / \text { frame }\end{array}$ & $7.6 \pm 4.6$ & $4.5 \pm 2.4^{\#}$ & $5.6 \pm 3.7$ & $7.0 \pm 3.6$ & $6.5 \pm 2.7$ \\
\hline \multicolumn{6}{|c|}{$\begin{array}{l}\text { * } \mathrm{P}<0.05, \# \mathrm{P}<0.0001, \text { Comparison between studied groups and controls (Kruskal-Wallis } \mathrm{H} \text { test with } \\
\text { Bonferroni post hoc analysis). }\end{array}$} \\
\hline
\end{tabular}

\section{Figures}



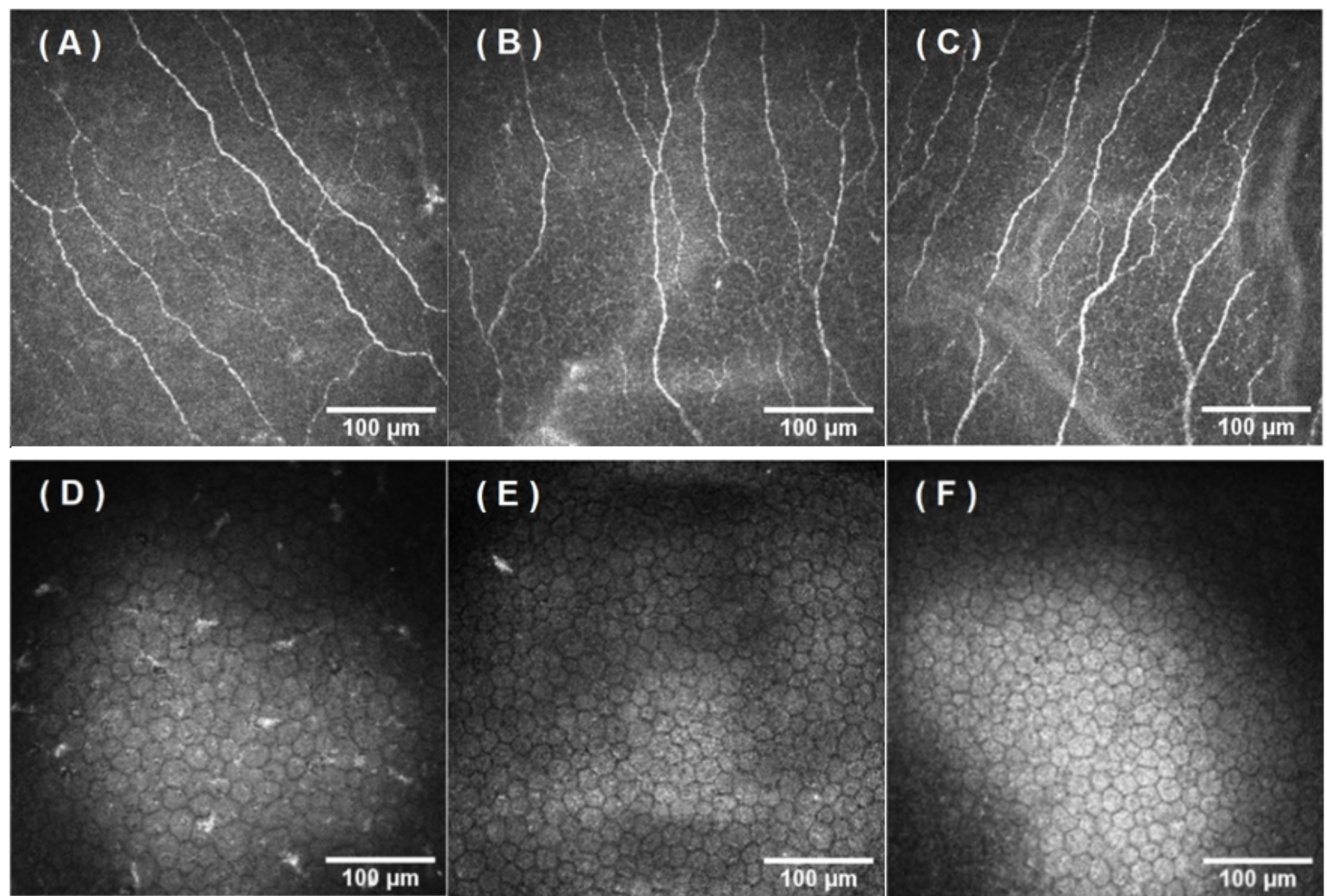

( $F)$

\section{Figure 1}

In vivo confocal microscopy images obtained at the level of the endothelial cell layer and sub-basal nerve plexus. (A) Decrease in density and number of nerves in the affected eye of a patient with PSS. (B) Decrease in density and number in the contralateral clinically unaffected eye of a PSS patient. (C) Normal corneal sub-basal nerve plexus of a patient of the control group. (D) Decreased ECD in the affected eye of a patient with PSS. (E) Endothelial cells layer in the contralateral clinically unaffected eye of a PSS patient. (F) Normal endothelial cells layer of a patient of the control group.

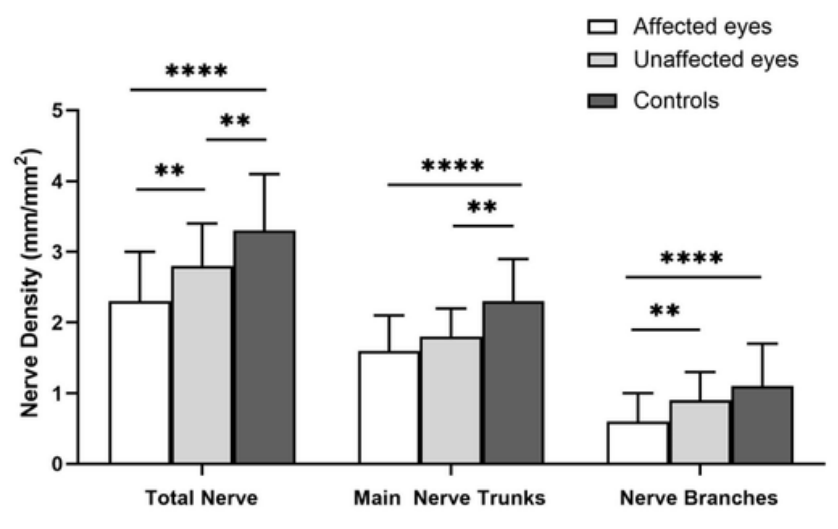

A) Nerve Density

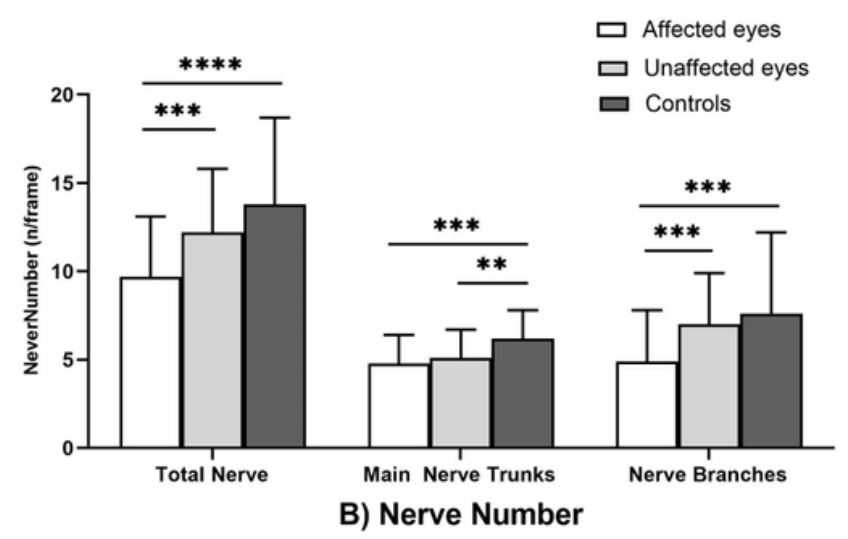


Figure 2

Reduction of CSN in affected and contralateral unaffected eyes in PSS patients and control subjects. (A) The density of the total nerves, the main nerve trunks, and the nerve branches. (B)The number of total nerves, main nerve trunks, and nerve branches. Error bars represents standard deviation from the mean. ${ }^{\star *} P<0.03,{ }^{* \star *} P<0.006$, and ${ }^{* \star * \star} P<0.0001$ by analysis of Kruskal-Wallis $\mathrm{H}$ test.

\section{Endothelial Cell Density vs. Main Nerve Trunk Density}

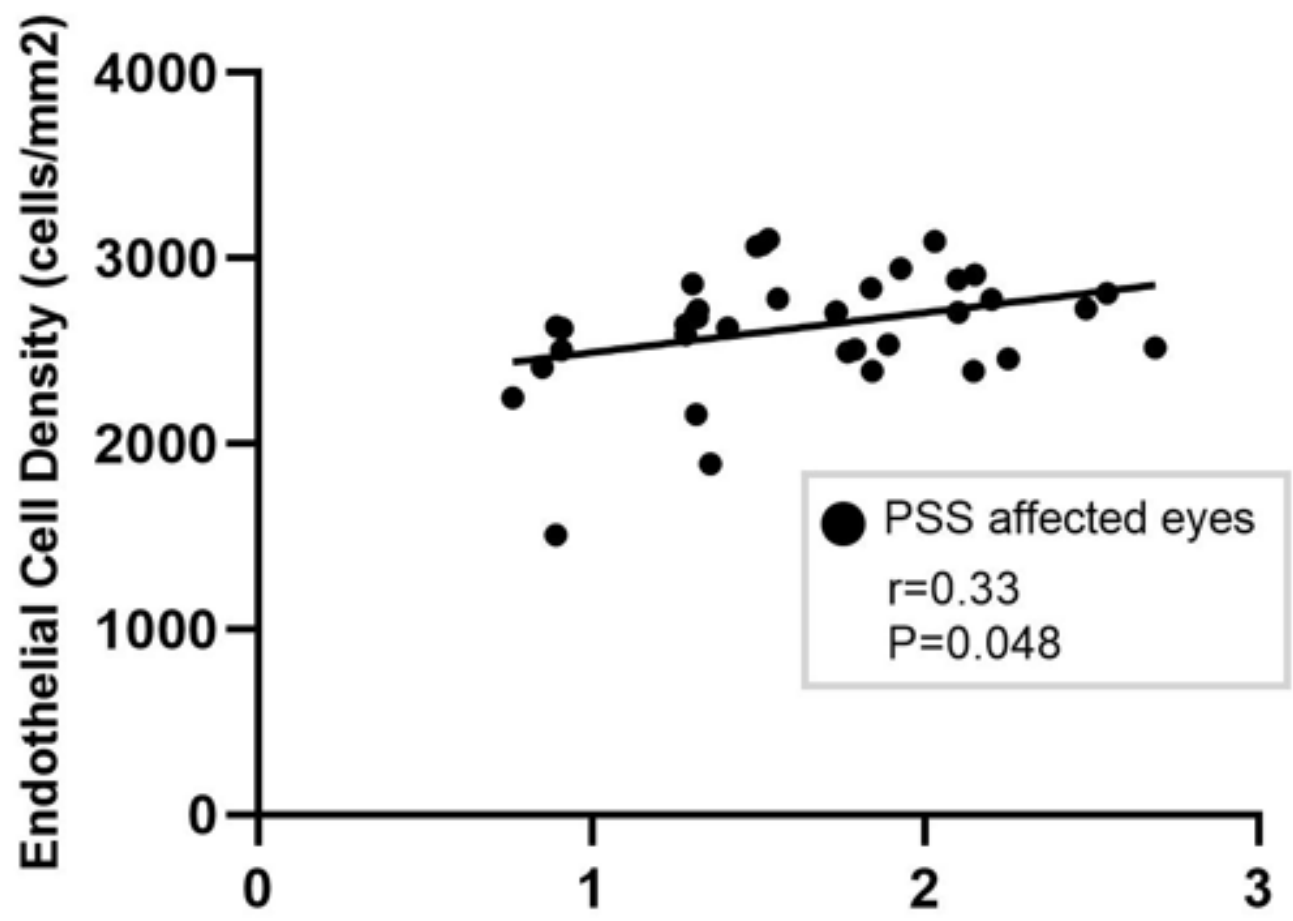

\section{Main Nerve Trunk Density}

\section{Figure 3}

The correlation between endothelial cell density and the density of main nerve trunks in the affected eyes of patients with unilateral PSS.
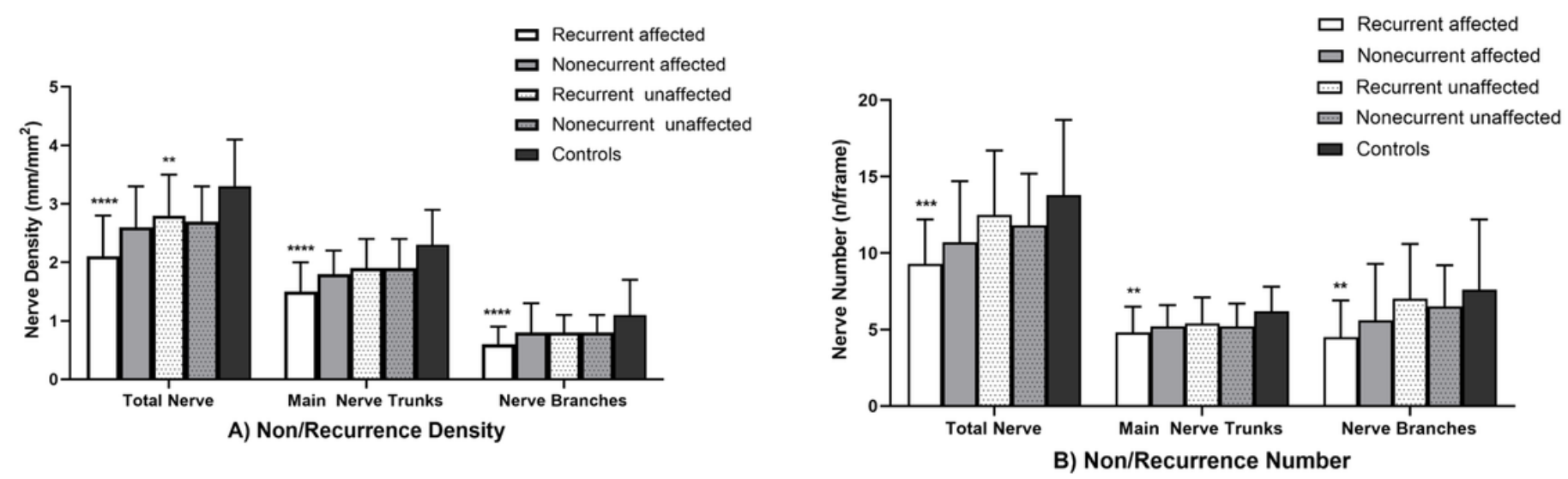


\section{Figure 4}

Reduction of CSNs in recurrence or nonrecurrence affected and contralateral unaffected eyes in PSS patients and control subjects. (A) The total nerves density, the main nerve trunks density, and the nerve branches density of the patients with recurrence or nonrecurrence PSS. (B) The total nerves number, the main nerve trunks number, and the nerve branches number of the patients with recurrence or nonrecurrence PSS. Error bars represents standard deviation from the mean. ${ }^{\star \star} P<0.04,{ }^{\star \star \star} P<0.001$, and $\star \star \star \star * P<0.0001$ compared with control group by analysis of Kruskal-Wallis $\mathrm{H}$ test. 